\title{
How spatial and compositional heterogeneities influence zinc retention in a simulated aquifer
}

\author{
MAYA ENGEL ${ }^{1,2}$, KRISTIN BOYE ${ }^{2}$, VINCENT NOEL ${ }^{2}$, \\ TRISTAN BABEY ${ }^{1,2}$, JOHN BARGAR ${ }^{3}$ AND SCOTT \\ FENDORF $^{1}$ \\ ${ }^{1}$ Stanford University \\ ${ }^{2}$ SLAC National Accelerator Laboratory \\ ${ }^{3}$ Stanford Synchrotron Radiation Lightsource (SSRL), SLAC \\ Presenting Author: mayaeng@stanford.edu
}

Alluvial aquifers play a vital role as sources of groundwater worldwide - and increasingly for managed water storage. Finegrained lenses of clay and organic matter, enriched in iron and sulfur, are common within aquifers and stimulate heterogeneous redox environments. Variation in redox conditions strongly influence biogeochemical cycling, heavy metal dynamics, and resulting groundwater quality. The complexity of these groundwater systems has rendered it highly challenging to predict the ultimate fate of heavy metals. Therefore, we examined the mobility and retention mechanisms of zinc in a simulated alluvial aquifer system consisting of fine-grained sediment lenses surrounded by coarse aquifer sand. The lenses promoted reducing conditions both within and in the succeeding sand, despite an inflow of oxygenated groundwater. Following the introduction of zinc-polluted groundwater, pore-water zinc concentrations gradually increased in the sand but were mostly undetectable within the lenses. Solid-phase analysis revealed that zinc preferentially accumulated in the lenses compared to the aquifer sand. Zinc EXAFS analysis was performed to explore the retention pathways of zinc, and distinct differences were observed in zinc speciation between the sand and the lenses. Substantial precipitation of $\mathrm{ZnS}$ was detected in the lenses, as a result of redox-triggered sulfide production, which likely masked the contribution of organic matter. Interestingly, the clay fraction was found to dominate zinc retention throughout the aquifer system - mainly through the association of zinc with 2:1 clay minerals and layered double hydroxides (LDHs). We also discovered that the first lens in the flow-path accumulated double the loading of zinc relative to the second lens - yet this relationship was only maintained for the Zn-clay/LDH fraction, and not for $\mathrm{ZnS}$, for which the loading remained comparable. This indicates zinc influent concentration controlled $\mathrm{Zn}$ clay/LDH formation whereas the extent of sulfide production controlled the quantity of $\mathrm{ZnS}$ formed. Zinc resistance to solidphase aqueous extraction but sensitivity to acid extraction suggests limited, but measurable, capacity for release and transport. 